\title{
Políticas alimentares: interações entre saúde, consumo e produção de alimentos*
}

Food Policy: interface between health, consumption and production food

Política de alimentos: interacciones entre la salud, consumo y producción de alimentos

Politique alimentaire: interactions entre la sante, consommation et de la production d'aliments

\author{
Rozane Marcia Triches** \\ (rozane.triches@gmail.com) \\ Tatiana Engel Gerhardt*** \\ (tatiana.gerhardt@ufrgs.br) \\ Sergio Schneider*** \\ (schneide@ufrgs.br)
}

Recebido em 16/12/2012; revisado e aprovado em 18/02/2013; aceito em 14/04/2013

\begin{abstract}
Resumo: Este trabalho buscou identificar como uma política alimentar integrada é aplicada e quais os elementos importantes que favorecem e determinam a sua efetivação. Analisamos o caso do município de Rolante, RS e verificamos que a intersetorialidade promoveu ações para o desenvolvimento local que reuniram estratégias inovadoras na saúde coletiva e no consumo dos escolares. Isso só foi possível a partir da percepção, do diálogo e da ação dos atores locais e na utilização efetiva dos programas estatais que gerenciam.

Palavras-chave: Alimentos. Saúde. Desenvolvimento.

Abstract: This study aimed to identify as an integrated food policy is applied and what the important elements that contribute to determine its effectiveness. We analyze the case of the city of Rolante, RS and verified that promoted intersectoral actions for local development bringing together innovative strategies in public health and consumption of school. This was only possible from the perception, dialogue and action of local actors and the use of effective state programs they manage.

Key words: Food. Health. Development.

Résumé: Cette étude visait à identifier comme une politique alimentaire intégrée est appliquée et quels sont les éléments importants qui contribuent et qui déterminent son efficacité. Nous analysons le cas de la ville de Rolante, RS et vérifié que la promotion des actions intersectorielles pour le développement local réunissant des stratégies novatrices en matière de santé publique et de la consommation de l'école. Cela n'a été possible de la perception, le dialogue et l'action des acteurs locaux et l'utilisation efficaces des programmes étatiques qu'ils gèrent.

Mots-clés: Alimentation. Santé. Développement.

Resumen: Este estudio tuvo como objetivo identificar como una política alimentaria integral se aplica y cuáles son los elementos importantes que contribuyen y que determinan su eficacia. Se analiza el caso de la ciudad de Rolante, RS y verificó que promueve acciones intersectoriales para el desarrollo local que reúne a estrategias innovadoras en salud pública y el consumo de la escuela. Esto sólo fue posible a partir de la percepción, el diálogo y la acción de los actores locales y el uso efectivos de programas estatales que gestionan.

Palabras clave: Alimentación. Salud. Desarrollo.
\end{abstract}

\section{Introdução}

Tem sido cada vez mais evidente a relação entre o modelo agroindustrial de produção de alimentos, caracterizado pela padronização, globalização, verticalização e cadeias longas de abastecimento com o consumo de gêneros altamente processados e consequentes problemas de saúde como o sobrepeso e as doenças crônico-degenerativas
(GOODMAN; DUPUIS, 2002; GOODMAN, 2002). Outras implicações relacionadas ao sistema agroalimentar contemporâneo dizem respeito à pobreza, às dificuldades de sobrevivência e à exclusão de pequenos agricultores (VAN DER PLOEG et al., 2000), às questões de transição nutricional (MONTEIRO; CONDE; POPKIN, 2002; KAC; VELÁSQUEZ-MELÉNDEZ, 2003), insegurança alimentar e aos " food scares" (FINE, 2004). Nessa íntima relação, há

\footnotetext{
* Artigo produzido com base na tese de doutorado "Reconectando a produção ao consumo: a aquisição de gêneros alimentícios da agricultura familiar para o Programa de Alimentação Escolar", defendida em 2010 no Programa de Pós-Graduação em Desenvolvimento Rural da UFRGS.

** Universidade Federal da Fronteira Sul (UFFS), Realeza, PR, Brasil.

*** Universidade Federal do Rio Grande do Sul (UFRGS), Porto Alegre, RS, Brasil.
} 
ainda que se fazer referência aos prejuízos ao meio ambiente, como a perda da biodiversidade, a poluição, o aumento da produção de lixo, a escassez de água, entre outros (LANG; HEASMAN, 2004; GOODMAN; REDCLIFT, 1991).

Esses problemas atuais servem como base para refletir sobre o desenvolvimento e a saúde não de forma reducionista, mas interligada. Se grande parte dos problemas de saúde é gerada pelo meio em que se vive e, destes, considera-se a alimentação o principal contribuinte, então, pensar a saúde da população é pensar o modelo agroalimentar e, consequentemente, o modelo de desenvolvimento que a sociedade pretende. Ou seja, no centro deste debate, as dietas seriam causa e consequência de um modelo produtivo que oferece gêneros baratos, dominados por grandes e poucas indústrias de processamento e varejo que têm o poder de influenciar nas escolhas alimentares da população. Ao considerar a alimentação como uma questão social, ela se torna também uma questão pública, remetendo-a ao foro do Estado e de sua responsabilização para com o dever de promover ambientes que propiciem o bem-estar dos cidadãos.

Nos debates sobre desenvolvimento rural sustentável, tem-se defendido a mudança paradigmática do modelo produtivista para outro modelo que, entre outras transformações, reconecte a produção ao consumo de alimentos (ILBERY et al., 2005). Essa reconexão não só faz referência ao encurtamento da cadeia de abastecimento alimentar e à localização, mas também remete à reflexão teórica sobre a interdependência entre esses dois domínios na construção de novos padrões de produção e consumo, já que modelos específicos de consumo promoveriam modelos específicos de produção e vice-versa (GOODMAN; DUPUIS, 2002; SLEE; KIRWAN, 2008).

Tomando como base a perspectiva da criação e recriação de instituições (reproduções e consensos), é possível considerar que um novo modelo produtivo possa ser concretizado a partir de uma nova demanda e que essa possa ser cultivada pela ação do Estado, via programas de saúde e alimentares. Portanto, conjuntamente ao propósito de mudança estrutural relativa à produção de alimentos, é necessária uma mudança estrutural relati- va ao consumo, que é um elo importante na reordenação dos sistemas alimentares.

Nesse raciocínio é que a preocupação em relação ao consumo de alimentos interliga-se com as discussões sobre saúde coletiva e as concepções, os princípios e a operacionalização da promoção da saúde. Na construção original do termo, promover a saúde estaria associado aos fatores gerais de determinação da saúde, no entanto a concepção difundida privilegiou os fatores particulares, priorizando medidas preventivas e programas educativos que trabalhavam com mudanças comportamentais e de estilos de vida em uma perspectiva behaviorista (CARVALHO, 2004). Segundo Sícoli e Nascimento (2003), vários autores e até a OMS criticam essa postura pela responsabilização individual e a culpabilização ao considerar as pessoas como responsáveis exclusivos pela saúde, desatrelando as determinações sociopolíticas e econômicas.

Retomando a concepção original, a promoção da saúde estaria vinculada não mais a um paradigma médico baseado na erradicação das doenças nem a outro pautado na prevenção via condutas pessoais, especialmente com grupos de risco, mas a um terceiro que responderia pelos problemas socioambientais, visando à criação de entornos físicos e sociais que favorecessem a saúde e o bem-estar dos indivíduos. Para tanto, as ações envolveriam medidas políticas intersetoriais que se destinassem a mudanças sociais e se fundamentariam no trabalho comunitário. Salienta-se dessa forma, segundo a World Health Organization (1998) a vinculação da concepção da promoção da saúde a princípios como: integralidade, intersetorialidade, equidade, sustentabilidade, formação de redes sociais, participação social e empoderamento.

Todas essas discussões vêm sendo reunidas sob uma concepção mais ampla e mais abrangente do que se entende atualmente por "segurança alimentar e nutricional". Enfoca-se o direito à alimentação (não só em quantidade suficiente, mas também de qualidade, e de forma permanente), à soberania alimentar, à preservação da cultura alimentar de cada povo e à sustentabilidade do sistema alimentar. Essa complexidade e as diferentes concepções sobre o tema, segundo Anjos e Burlandy (2010), ainda mantém a SAN como um conceito em construção. No entanto é 
bastante distinto de uma concepção restrita à temática da fome, da escassez produtiva e do acesso à alimentação, bem como do foco apenas na discussão do consumo ou do estado nutricional (em suas diferentes manifestações como obesidade, desnutrição, carências de micronutrientes), ou ainda do alimento seguro. Por conseguinte, o enfoque de SAN é caracterizado especialmente pela perspectiva de compreender de forma integrada as questões referentes às múltiplas dimensões do sistema agroalimentar (produção, abastecimento, comercialização e consumo), com base nos princípios que pautam o conceito, quais sejam: direito humano à alimentação adequada; soberania alimentar; intersetorialidade; equidade; participação social.

Considerando essas abordagens, este trabalho buscou identificar como uma política integrada é aplicada e quais os elementos importantes que favorecem e que determinam a sua efetivação. Essas percepções se tornam relevantes na medida em que a praticabilidade da intersetorialidade sempre foi um desafio, além do que experiências que tratem os problemas sociais, econômicos e de saúde de forma interligada são raros. Nesse sentido, buscamos analisar o caso do município de Rolante, RS, que vem tentando implementar a política de segurança alimentar, vinculando programas alimentares como o Programa de Alimentação Escolar (PAE) e de saúde como a Estratégia Saúde da Família (ESF) desde 1998.

Primeiramente, pretende-se fazer uma discussão amparada em alguns autores que defendem o papel do Estado e sua responsabilidade sobre a saúde e, portanto, sua necessária intervenção no consumo da população para, depois, contrastá-la com a prática realizada em Rolante. Esse debate vem de encontro à análise de que a aquisição de produtos da agricultura familiar ${ }^{1}$ via PAE interliga-se com uma nova concepção do Estado relativa à saúde e ao consumo sustentável (MORGAN; SONNINO, 2007; TRICHES; SCHNEIDER, 2010). Essa nova concepção partiria da abordagem que associa os problemas de saúde

\footnotetext{
${ }^{1}$ Em 2009, os processos de aquisição pública para o PNAE que até então estavam associados exclusivamente à Lei $8.666 / 93$, passam a ser também normatizados pela Lei 11.947/09, tornando obrigatória a utilização de no mínimo $30 \%$ do recurso do FNDE na aquisição de gêneros alimentícios de agricultores familiares.
}

não só a aspectos individuais e biológicos, mas, principalmente, a aspectos sociais, econômicos, culturais e políticos relacionados aos modelos de produção e consumo existentes.

\section{A relação entre políticas alimentares, saúde, consumo e produção de alimentos}

As formas atualmente recorrentes de pensar o consumo de alimentos e a saúde são restritas a uma visão biomédica e individualista. Mais especificamente, o campo da ciência da nutrição, como em outras disciplinas, especializou-se e empenhou-se em compor padrões nutricionais uniformes para a saúde, baseados na biologia, na genética, na bioquímica e na fisiologia. No entanto, segundo Mennell, Murcott e Oterloo (1992), embora as pessoas conheçam as regras nutricionais, observa-se que não as colocam em prática. Essa constatação e as pesquisas sobre consumo que têm relacionado os problemas alimentares e de saúde às condições de vida da sociedade moderna industrializada, culminaram com o reconhecimento dos aspectos sociais da alimentação.

As políticas públicas, por sua vez, a partir dos anos de 1980, passaram a seguir as recomendações da Food and Agriculture Organization (FAO) e da World Health Organization (WHO), que propunham melhorar ou ampliar a qualidade de vida das pessoas, ajudando-as a viverem independentemente das instituições, mas tendo habilidades financeiras e físicas para escolherem, com responsabilidade, suas próprias refeições e alimentos.

No entanto, para Fischler (1995), ao levar as decisões para o nível individual, em que, até então, o grupo, a família, a tradição e a cultura impunham seus determinismos, tornou a autonomia portadora de anomia, ou seja, não há critérios para tomar essas decisões, o que provoca consequências importantes nas representações e práticas em matéria de alimentação. Além da falta de critérios, Fischler aponta para o conflito entre os especialistas e cientistas. Para ele, o Estado, os movimentos dos consumidores, os médicos das diversas especialidades, os industriais, a publicidade e os meios de comunicação contribuem para deixar as pessoas confusas e lidando com várias contradições. 
Lang e Heasman (2004) e Lang et al. (2009) também defendem que o tratamento dos problemas alimentares e nutricionais deveriam ser realizados de forma mais holística, gerenciando os desafios alimentares em conjunto, considerando desde a forma em que o alimento é produzido até como ele é tratado pelo consumidor. Segundo o ideário liberal, qualquer intervenção política em relação às escolhas dos indivíduos estaria condescendendo com a ideia de que ele é uma vítima, mais do que um consumidor inteligente. Os autores argumentam que esse posicionamento ignora as realidades e a escala da crise alimentar e de saúde que está além de qualquer indivíduo, e também ignora as relações de poder que moldam o abastecimento alimentar.

Estes autores defendem a existência de uma crise no modelo dominante de abastecimento alimentar e a formulação de políticas públicas que providenciem soluções que tratem das diversas doenças associadas com alimentos e também com o meio ambiente. Elencam e caracterizam três principais paradigmas: o produtivista, o das ciências naturais e o ecológico. Convém salientar os dois últimos, em que ambos encontram a biologia como central, mas o das ciências naturais crê na biologia como controladora das relações entre saúde e alimentos, enquanto o ecológico vê essa posição como um reducionismo biológico. Entre esses dois paradigmas, tanto quanto o produtivista o primeiro trabalha "sobre" a natureza, enquanto o segundo trabalha "com" a natureza.

Na retórica neoliberal, os consumidores são considerados peças-chave para o mercado ser eficiente. No entanto, na prática, eles têm poucas informações e muitas vezes essas informações são padronizadas e veiculadas pelo marketing. As escolhas, principalmente por crianças, são facilmente influenciadas por intensas propagandas. Dessa forma, passa a ser central nessa discussão a pergunta: a saúde é uma decisão e responsabilidade individual?

Diante dessas perspectivas, o Estado, por intermédio de seus programas e políticas, dentre os quais os referentes ao consumo alimentar de populações, como a alimentação escolar, teria o poder de influenciar as práticas e escolhas de consumo, moldando o sistema agroalimentar e a saúde das populações. Se considerar que o público-alvo são crianças (escolares), que, geralmente, não têm o poder de decisão e são influenciadas em suas escolhas de consumo, deve se salientar ainda mais a importância desse controle, principalmente porque hábitos, comportamentos e preferências adquiridos na infância moldariam, em parte, as que seriam mais facilmente mantidas até a fase adulta, criando padrões que se tornariam resistentes à mudança. Freedhoff e Hébert (2011) alertam ainda, para o fato da influência das próprias indústrias de alimentos sobre o Estado e suas políticas de forma a utilizá-los a seu favor.

Por outro lado, no estudo de Morgan e Sonnino (2007) sobre os programas de alimentação escolar da Itália e do Reino Unido, os autores destacam que em ambos os locais o Serviço de Alimentação Escolar estava sendo utilizado para "empoderar o consumidor" por meio do uso de programas educacionais, em que a mensagem das aulas surtia efeitos na cantina. As escolhas eram restritas de forma a ajudar a promover padrões de alimentação adequada relacionando-as ao consumo de alimentos da cultura local. A racionalidade dessa abordagem, salientam os autores, é que as escolhas informadas pressupõem algum conhecimento do que são ou não as dietas adequadas que precisam ser adquiridas (em casa e na escola), e, portanto, antes disso, é necessário adquirir a capacidade de exercer essa escolha.

Portanto o processo de educação nutricional não seria apenas uma injunção convencional da indústria de promoção da saúde para "comer menos e se exercitar mais", mas ele se constituiria em um aprendizado sobre a produção local e a valorização da diversidade cultural alimentar. O objetivo dos programas educacionais seria o de promover conhecimento aos consumidores dando-lhes consciência sobre o que estão consumindo, bem como criar um compromisso com alimentos com paladares e características produzidas localmente.

Para Morgan e Sonnino (2007), consumidores com discernimento para esse tipo de demanda é o fator mais importante para criar e manter hábitos alimentares adequados para o corpo e para o ambiente. Por um lado, favorecendo o consumo de alimentos mais frescos, naturais e sazonais e a saúde e, por outro, 
incentivando cadeias curtas de abastecimento e formas de produção mais adequadas do ponto de vista social e ambiental.

Pretende-se salientar com isso a importância de entender como vem sendo construídas no Brasil experiências que interliguem os programas e políticas do Estado de forma a promover desenvolvimento local em seus múltiplos aspectos - econômicos, sociais, culturais, ambientais e de saúde e bem-estar da população.

\section{As duas faces de uma mesma moeda: as políticas alimentares na determinação da saúde e do desenvolvimento}

Ao salientar a importância do Estado como orientador das escolhas alimentares por seu poder de interferência e seu dever relativo ao bem-estar da população, verificou-se que, em Rolante, RS, a estratégia de modificar a estrutura, objetivando, em princípio, um novo modelo de desenvolvimento rural, passou pela astuciosa verificação de que isso não seria possível sem o auxílio da demanda. Esse objetivo de envolver a comunidade em uma perspectiva de moldar novas relações de produção e consumo em uma miríade de ações que perpassariam os domínios estritos de uma entidade, fez com que a Emater em conjunto com as Secretarias de Educação e Saúde elaborassem um projeto chamado "Segurança Alimentar: Consolidando a Solidariedade e a Integração Institucional".

Para tanto, ultrapassou-se a fragmentação e desarticulação do modelo tradicional de gestão, para outro fundado na intersetorialidade de forma a propiciar negociações entre os diferentes atores sociais da arena política para sensibilizar e articular outros, permitindo ampliar a extensão da iniciativa e dar conta do problema de maneira mais efetiva.

Essa discussão que os extensionistas da Emater passam a fazer em Rolante, não é de forma a implantar uma intervenção, mas, sim, de legitimar as ações que já vinham ocorrendo e interligá-las em uma linguagem comum e com sentido. Conforme depoimentos, em um dos primeiros momentos de aproximação entre os diversos setores, o tema sobre segurança alimentar e nutricional (SAN) foi discutido de forma que todos os participantes relatassem as atividades realizadas por eles em relação a isso. Essas provocações resultaram em um conceito de SAN que reforçou as oficinas da $\mathrm{Cuca}^{2}$, a aquisição de produtos para a alimentação escolar de agricultores familiares, as ações de agentes de saúde, as atividades com sementes crioulas e as pesquisas sobre indicadores de longevidade, amamentação e mortalidade infantil.

Uma das perguntas a ser respondida era: "tu podes produzir xis produto, mas ele está chegando à mesa do consumidor do município?" (Extensionista Rural 1). Passavase a integrar uma lógica que até então estava desconexa. A produção interna não estava chegando à mesa do munícipe, porque ocorria um processo intermediário que os distanciava e provocava problemas a ambos, produtores e consumidores. Em outras palavras, as cadeias convencionais de abastecimento alimentar (de grande escala e longas) que estariam ligadas aos prejuízos à saúde poderiam ser substituídas por cadeias locais (de pequena escala e curtas) que, além de potencialmente melhorarem esse aspecto, também poderiam providenciar a inserção de agricultores familiares locais e beneficiar o ambiente.

\subsection{A Estratégia Saúde da Família: relação entre saúde e produção de alimentos}

Nessa linha, as ações realizadas pela ESF e os Agentes Comunitários de Saúde (ACS) de Rolante, vinculados à Secretaria de Saúde, destacam-se pela forma diferenciada de atuação e mediação desses profissionais junto à comunidade (principalmente rural), vindo ao encontro das propostas e de uma nova concepção de promoção à saúde. Percebe-se, nos depoimentos da Coordenadoria da ESF em Rolante, uma retórica que distingue um paradigma de saúde centrado no curativo e outro centrado no preventivo, cuja característica principal está nos cuidados com a alimentação.

Não se estranharia esse discurso entre os profissionais de saúde que há tempos o vêm fazendo, mas sim o seu caráter contestatório, que reflete como as polí ticas interferem

\footnotetext{
2 Pão doce tradicional alemão, elaborado com farinha de trigo, leite, ovos e açúcar e outros ingredientes, com recheios diversos e cobertos com farofa de farinha de trigo, manteiga e açúcar.
} 
diretamente no direcionamento de determinadas práticas. Para a própria Coordenadoria, políticos desejam apenas resultados imediatos e, por isso, não há motivos para prevenção e promoção de saúde, pois nenhuma dessas ações tem resultados visíveis revelando-se aos eleitores. Em suas palavras os políticos “[...] não veem que as pessoas mais saudáveis no futuro vão gastar menos remédio. É mais fácil dar remédio do que falar na prevenção" (Gestor permanente 4).

Morgan (2006) aponta para a negligência das convencionais análises de custo/ benefício que têm dificuldades em quantificar os benefícios de uma boa alimentação e de hábitos saudáveis, muito dos quais ocorrem em longo prazo. Enfatiza a questão do custo de uma vida inteira aos cofres públicos, que, segundo o autor, seria um dos mais importantes ingredientes da receita de cadeias alimentares sustentáveis. Investir em alimentos "bons", considerados aqui como saudáveis e adequados do ponto de vista ambiental e cultural, em detrimento dos industrializados, seria a forma mais econômica de investir em saúde.

Além de política, bem frisa a coordenadora do ESF, há também uma questão social: "As pessoas têm dificuldade de fazer modificações dentro da família. Em vez de dar salgadinho, dar... na realidade é a sociedade, é uma questão social". Para ela, existe uma variedade de apelações relativas à comodidade e ao desmerecimento da agricultura: "quem quer perder tempo para poder se dedicar a essas coisas? Por quê? Porque não se dá valor a isso - vou e compro, é mais fácil".

Dessa forma, dois pontos principais se destacam. O primeiro diz respeito a uma nova visão de Estado, ou mais especificamente, uma nova visão política sobre saúde, que ultrapasse o simples interesse imediatista e setorial. O segundo refere-se a uma interferência social/cultural que dê às pessoas condições de tornarem-se cidadãs e não apenas consumidoras, tendo consciência da consequência de suas escolhas alimentares. A postura desse profissional demonstra a incorporação de uma concepção de promoção à saúde que se coaduna com aquela que privilegia os fatores gerais e intersetoriais, e não somente os do setor saúde na sua determinação. Dessa forma, percebe-se uma tendência a trabalhar aspectos de saúde de forma a vislumbrar o diálogo com os setores econômicos, sociais e ambientais que a determinam.

Esses princípios podem ser verificados a partir de sua operacionalização em Rolante junto à ESF, com o projeto de resgate das sementes crioulas e a utilização delas para plantio e consumo pelas famílias atendidas e a forma particular de alguns agentes de abordar as questões de alimentação junto à população.

Nos depoimentos dos entrevistados, observou-se que a distribuição pelos agentes comunitários de sementes crioulas objetivava a diversificação da alimentação, o incentivo da produção para subsistência e da conscientização da população da importância de cultivos que fugissem da dependência do mercado, buscando soberania alimentar.

Importante salientar a ligação que esse projeto faz entre a saúde, os alimentos e o ambiente, trabalhando de forma a integrá-los. Nessa perspectiva, o modelo de produção e de abastecimento de alimentos estaria ligado diretamente à saúde, que não é tratada por meio de um reducionismo biológico, mas dentro de um "paradigma ecológico integrado" na perspectiva de Lang e Heasman (2004). Isto fica explícito nas palavras do agente de saúde: "Eu vou difundindo essas sementes [...] elas resistem mais. A natureza tem a lei própria dela. E de onde eu tiro meu alimento - da natureza. Ah, mas eu domino a natureza! Calma lá, não é bem assim. Quem diz que domina a natureza, é ignorante". O agente de saúde defende a autogovernabilidade da natureza e a utilização dessa sabedoria pelo homem, o que viria de encontro à tese de trabalhar "com ela" e não "sobre ela".

Segundo o próprio ACS, que atende uma área rural, há a produção de linhaça orgânica que é utilizada para outras finalidades (consumo animal, produção de vassouras), mas não aproveitada para consumo humano. Por outro lado, a produção de alimentos vem utilizando cada vez mais agrotóxicos e há muitos agricultores apresentando problemas de saúde em virtude desse contato, apontando a incoerência da ação humana na utilização dos recursos naturais que reverte em uma piora do quadro de saúde no que tange às doenças advindas da má alimentação.

Com todas as informações, com o agente batendo na porta, todo mês dando o remédio. Grosso modo não funcionou. A gente 
tem condições de mudar. [...] Eu tô vendo assim, o mundo é dos incoerentes mesmo. Eu tô produzindo um alimento que podia ser orgânico, mas eu crio com o meu modo de produção, eu faço esse cara adoecer e eu jogo esse cara no sistema de saúde. Isso dá agonia. (Gestor Atual 4).

Esse depoimento explicita uma reflexão do agente de saúde referente à defesa de um consumo sustentável que partilha de preocupações que relacionam as práticas de produção às questões de saúde e às questões ambientais. Entende-se que o Estado tem sido negligente ou tem se equivocado na forma de tratar com a saúde e com os modelos agroalimentares, incentivando, em última instância, o acréscimo de doenças por duas vias - pela forma como são produzidos os alimentos e pelo consumo de gêneros alimentícios provenientes desse modelo. Nesse sentido, defende que isso advém da complexificação do sistema em detrimento de sua simplificação. Exemplo da escolha por produtos com agrotóxicos e industrializados do que por produtos, como as sementes crioulas, a linhaça (orgânica) e outros gêneros, produzidos pelos próprios agricultores e desvalorizados por eles mesmos. Diante das consequências desse modelo, sente-se impotente visto que, mesmo diante de suas intervenções na população rural, não se tem conseguido controlar a incidência das enfermidades.

No entanto essas reflexões e entendimentos do agente de saúde revelam, por si, aspectos de interface inovadores em relação às suas intervenções nas famílias que atende. Uma história contada por ele traz elementos que exemplificam como os agricultores se relacionam com o modelo cultural de consumo e as formas como ele atua para reverter a situação que considera errônea.

Tem um senhor lá que bota uns 10 abacates dentro de um saquinho, vem pro centro vender aqui e compra refrigerante de litrão pra dá pros netos no final de semana. E daí começa o choque, como é que eu vou chegar e dizer pra ele: olha o senhor não deve fazer isso. O que eu vou colocar pra ele: eu vou lá e quero saber como se produz o abacate. Porque ele não sabe ler, tá, daí eu digo, o abacate é muito bom porque a gordura do abacate é melhor que a gordura da carne, porque não fica tudo no organismo. Falei tudo pra ele do jeito que ele entendia. E ele sabe que a gordura entope as veias, porque o vizinho tá lá andando todo torto porque teve um derrame. [...] A gente sabe como se produz abacate, não precisava ele ficar me dizendo, mas assim a gente já fala outras coisas e ajuda a melhorar a autoestima dele. Na terra dele ele é pós-graduado. Tem que respeitar isso também. Essa aprendizagem dele, não essa gama de informações da mídia controlada, o que ele aprendeu, pô tem que valorizar. Ele quer agradar, ele quer que os netos dele fiquem do lado dele, por isso ele vende os abacates pra comprar refrigerante. Ele não tem noção de que os netos são vítimas do êxodo rural. (Gestor Atual 4).

O agente consegue entender a condição do agricultor que, diante de uma cultura de consumo dominante, tenta agradar os seus netos, trocando um alimento "saudável" por outro "não saudável", sem se dar conta do que está por trás dessa troca. Se os netos preferem refrigerante é porque, em meio a uma cultura alimentar dominante, a propaganda e o paladar para esse alimento estariam sendo incentivados em uma dinâmica em que as escolhas são feitas de forma massificada em detrimento de outra vinculada à cultura ou tradição.

Não obstante, o agente não o trata como uma pessoa ignorante, mas como alguém que possui outros tipos de conhecimento e tenta valorizá-los. Dessa forma, pressupõe que seus conhecimentos também serão valorizados pelo agricultor, havendo uma troca de ativos. A interferência do agente de saúde nesse processo intenta, de alguma forma, transformar essa escolha em algo produtivo, não desaprovando as escolhas consideradas ruins, mas incentivando as consideradas boas com uma atitude persuasiva em relação à qualificação nutricional em uma tentativa de valorizar os alimentos produzidos pelo próprio agricultor.

Essa forma de intervenção vai além do simples repasse de informações para induzir determinados comportamentos, mas busca apoiar pessoas e coletivos a realizarem suas próprias análises para que tomem as decisões que consideram corretas, desenvolvendo a consciência crítica e a capacidade de intervenção sobre a realidade. Nessa perspectiva, não há desigualdade entre profissionais e usuários, mas uma parceria entre eles em uma forma de educação que procura romper com métodos educativos centrados no exercício 
do "poder sobre" o outro, substituindo-o por métodos que valorizam o debate e a discussão de ideias, as opiniões e os conceitos com vistas à solução de problemas em uma distribuição de poder.

Essas novas formas de abordagem de educação em saúde sugerem um aprendizado que se dá a partir de um processo social. A erosão das regras sociais e normativas que, até então, balizavam-se na tradição somada à homogeneização da cultura de massa e à ignorância ou confusão de regramentos de saúde, viabilizariam escolhas alimentares que determinariam um quadro de saúde preocupante, necessitando formas de intervenção mais efetivas. Além disso, a estratégias pensando a mudança nos comportamentos e os modelos alimentares, não só procuraram atingir o público adulto, mas principalmente, o público infantil a partir do Programa de Alimentação Escolar.

\subsection{Programa de Alimentação Escolar:} moldando escolhas para o desenvolvimento local

Com essa lógica de promoção à saúde e com o propósito de alcançar principalmente as crianças, ao reunir as Secretarias para discutirem o conceito de SAN, passa-se a reiterar as ações relativas à aquisição de produtos da agricultura familiar para a alimentação escolar que ocorriam desde 1998. Em 2003, segundo dados do município, o comércio varejista fornecia $84 \%$ dos alimentos para a alimentação escolar, enquanto a agricultura familiar respondia com os $16 \%$ restantes. Já em 2008, 32\% do recurso federal/municipal remetido à alimentação escolar era utilizado para compras da agricultura familiar. Os alimentos citados como já fornecidos por eles foram: hortaliças, frutas, feijão, pipoca, chimia, farinhas integrais de milho, trigo e aveia, sucos, milho verde, mel, aipim, batata e biscoitos.

Diversas atividades realizadas com os escolares passaram a incorporar o olhar da política de SAN, de forma a modelar as suas escolhas. $\mathrm{O}$ gestor passa a direcionar as suas estratégias, pois vê a necessidade de conscientizá-los sobre as questões nutricionais, a valorização dos alimentos produzidos localmente, o resgate de hábitos como o da própria produção de verduras e as prepara- ções típicas, e sobre os cuidados com o meio ambiente.

Como já citado, um dos valores do livre mercado é a liberdade de escolha. No caso da alimentação escolar, a posição do Estado em conduzir e institucionalizar determinados tipos de comportamentos em relação a isso pode efetivar-se de diversas formas, como se exemplifica no caso de Rolante: desde a questão das cantinas e dos tipos de alimentos oferecidos na alimentação escolar, até as formas de intervenção, feitas tanto formal, quanto informalmente, junto aos alunos no sentido de educá-los e conscientizá-los no que tange ao consumo e à saúde.

Em relação às cantinas e aos lanches alternativos à alimentação escolar servida, verificou-se uma controvérsia. Segundo a nutricionista, existiam três escolas com barzinho, mas, em cumprimento à Lei estadual $13.027 / 2008$, todas deveriam adaptar-se em 2009 às novas regras. Segundo ela, uma reunião teria sido realizada com todos os diretores das escolas oficializando a divulgação da nova regulamentação.

No entanto observou-se que ainda há uma flexibilização do gestor em relação a isso, permitindo que as escolas utilizem a cantina para angariar fundos para as Associações de Pais e Mestres (APMs). Além disso, os alunos podem trazer alimentos "não saudáveis" para a escola, o que, segundo depoimentos, é uma prática frequente e, em relação a ela, algumas direções mostram-se contrárias, mas muitas vezes impotentes.

O envolvimento dos pais nessas escolhas ainda parece ser restrito, o que se deve tanto pelo escasso interesse deles em participar, quanto pelo pouco esforço do poder público em atraí-los, frustrando-se em parte a corresponsabilização de ambos pelo processo. Os pais entrevistados parecem depositar confiança e até julgam a escola um local onde seus filhos se alimentam ou passam a consumir alimentos mais saudáveis do que em casa.

Mas, por outro lado, a nutricionista considera que a proibição de os alunos trazerem alimentos não saudáveis não teria amparo legal e não seria algo tranquilo, já que, além dos alunos, também os próprios pais reclamariam, pois, segundo ela, eles não entenderiam a atitude, considerando-a até como uma afronta à liberdade de enviarem os alimentos que julgam 
adequados para o lanche dos filhos. Uma das diretoras entrevistadas corrobora essa questão, dizendo-se impotente em proibir os alimentos que outros pais enviam para a escola para o consumo dos filhos, temendo até represálias de alguns que se sentiriam afrontados, se houvesse alguma sanção nesse sentido: "Hoje eu fui numa sala e tinha refrigerante em cima da mesa. O que eu vou fazer? A gente não pode fazer nada" (Diretor 4).

Não ficou claro se a posição tomada pelos gestores seria a de evitar esses constrangimentos e confrontos com os pais ou se seria apenas uma forma de não causar desconfortos e continuar no comodismo de gerenciar o Programa apenas dentro de seus contornos legais sem assumir realmente uma atitude comprometida e dialogada com a sociedade.

Segundo Morgan (2006), os dois principais mantras ideológicos da indústria de "junk foods" são: (1) não há alimentos ruins, mas dietas ruins, e (2) as escolhas alimentares são questões privadas e não públicas. Em relação à primeira questão, parece haver consciência dos gestores públicos de que existem, sim, alimentos ruins e devem ser evitados. No entanto nem sempre eles se veem no direito de infringir o segundo mantra. Morgan defende que os altos custos de saúde pública das doenças relacionadas à dieta amplificam a questão do ambiente das escolhas alimentares e põe em xeque a alegação de que o Estado estaria invadindo a vida privada ao regular essas escolhas. Dado que o público em pauta são crianças e que cada vez mais cresce a responsabilidade do Estado na provisão alimentar dessa população (que permanece nas escolas e creches no mínimo quatro horas diárias, com uma tendência ascendente de público e de tempo), passa a ser questão de grande debate a divisão de trabalho entre o Estado e os indivíduos no desenho e desenvolvimento desses serviços públicos.

Dentro do marco legal e gerencial do PAE, no entanto, não parece haver omissão do poder público em Rolante em relação às escolhas alimentares que são feitas para os alunos. Dois pontos devem ser destacados nessa análise. O primeiro refere-se aos critérios utilizados para compor o cardápio e, nesse quesito, enfatizam-se as preocupações nutricionais que têm como coadjuvantes a aceitação pelos escolares, distinguindo-se as preocupações com o hábito e a cultura alimentar e a valorização dos alimentos locais. Em segundo lugar, diz respeito às estratégias de educação alimentar utilizadas pelos gestores para moldar o consumo e os hábitos alimentares dos alunos.

No que tange ao primeiro ponto, a escolha referente a que tipo de alimentação escolar será levada a termo é realizada pela Coordenação do Serviço, prioritariamente pela nutricionista em conjunto com a comunidade escolar, onde o CAE é um vínculo. No entanto, além dessa instituição, a comunicação com os merendeiros e diretores parece ser uma constante, o que acaba determinando, em grande parte, a constituição do cardápio.

Dessa forma, segundo a nutricionista, as escolhas atendem a certo tipo de restrição, pois, se os alunos pudessem escolher o cardápio, invariavelmente escolheriam alimentos com pouco valor nutricional. Segundo a visão das direções, merendeiras e pais, a escolha dos cardápios é realizada, pensando na questão nutricional e de saúde dos escolares. No entanto é de entendimento de alguns pais entrevistados, que essa preocupação se estende para a formação de hábitos alimentares e para a valorização dos produtos menos processados adquiridos de agricultores locais.

Nesse senso, a valorização do local, da cultura e da territorialidade passa também a ser importante critério, além dos aspectos nutricionais e sanitários, na hora de elaborar o cardápio, o que potencializa a escola como veiculadora de valores e direcionadora de escolhas. Segundo uma mãe, "é mais difícil aceitar o que é nosso, porque a gente sempre deixa o que é nosso de lado, a gente acha que o que vem de fora é mais importante" (Pai 4). Se uma instituição como a escola inicia a aquisição de produtos de agricultores da comunidade, às vezes conhecidos ou pais de alunos, há uma reavaliação do valor daqueles produtos e daqueles produtores que, até então, eram apenas considerados probos "colonos".

Mas, nas palavras dos próprios agricultores, para que essa valorização fosse efetiva, seria necessário, além do consumo desses alimentos, que os alunos fossem informados sobre quem os produz e sua procedência, o que pouco ocorre.

Teria que tê passado na teoria e na prática. Primeiro passar uma palestra dentro da sala de aula e depois visitar os colonos lá, dizer 
aqui vem a merenda de vocês. Só conhecem depois que ta na panela, raspadinho, lavadinho, eles não vão ver diferença. As crianças pequenas não têm noção do que que vem e o que eu to comendo. Depois já começam a querer escolher as coisinhas. (Agricultor Cooperado 2).

O depoimento desse agricultor coloca em cotejo a necessidade da conscientização e do conhecimento casados com o consumo e a atratividade da alimentação oferecida. Para desbancar a sedução dos alimentos vendidos nas cantinas, nos quais estaria embutido, além do apelo ao paladar, um status que nem todas as crianças poderiam acessar (e, por isso, passando a ser mais valorizados), haveria que se utilizar de outros mecanismos. Essa lacuna parece evidente dado que as respostas à pergunta realizada na entrevista sobre o reconhecimento das crianças em relação aos produtos advindo da agricultura familiar foi, em grande parte, negativa, ou seja, as crianças não sabem que o que consomem vêm de agricultores locais nem a importância disso. Os pais entrevistados, por sua vez, mostraramse sapientes da aquisição dos produtos dos agricultores, e afirmaram a importância dessa política, no entanto há que se considerar que esses pais foram escolhidos por conveniência, o que não permite generalizações.

Observa-se que há ainda uma confusão dietética constituída por uma mescla de interferências de estímulos de valorização local com interferências que as contradizem e que viabilizam o consumo de alimentos industrializados ou "massificados". Importante destacar que se verifica nesse caso uma tendência de desenraizamento alimentar, mas ainda com apelos tradicionais que se pretende manter.

Se manter a tradição é uma escolha reflexiva, embora existam contradições, é fato que, em Rolante, há atividades que configuram uma necessidade de cultivar a tradição alimentar, conjugando-o com outros aspectos relacionados às preocupações de ordem nutricional e ambiental. O PAE de Rolante reúne projetos que têm objetivos específicos, mas que apontam para a formação de hábitos alimentares saudáveis e adequados com uma visão que permeia a cultura e o ambiente.

Desses projetos vale referenciar a Oficina da Cuca, que se liga diretamente ao cultivo da tradição e da cultura alimentar do município, no sentido de valorizá-la e enraizá-la junto às crianças, não perdendo nem o conhecimento sobre a forma artesanal e original de confeccioná-las nem o paladar para essa preparação. Conjuntamente a essa oficina, atividades relativas ao meio ambiente são realizadas no mesmo local, enfocando as questões de produção orgânica de alimentos, além de práticas que teriam por finalidade o incentivo ao respeito e ao convívio de forma harmônica com a natureza.

Além desses projetos, cada unidade educacional tem uma atuação diferenciada em relação ao tratamento desses assuntos. Das seis escolas em que foram entrevistadas as direções, todas afirmaram abordar o tema de forma ou quotidiana e informal, como assunto permanente e transversal, ou com projetos, e, desses, o mais citado foi a horta escolar. O objetivo das hortas escolares, segundo as diretoras, seria o de "ensinar as crianças desde pequenininhas a importância de uma alimentação saudável, dá valor, aprender de onde vêm as coisas, porque, se a criança não tiver contato com isso, eles não sabem nem de onde vêm; valorizar a alimentação saudável" (Diretor 3).

Nesse caminho, Rolante foi mais longe e envolveu até os pais dos alunos. O curioso é que o Projeto chamado de Horta Escolar Familiar foi realizado com pais e alunos do meio rural e, segundo o Diretor responsável, os alunos não sabiam fazer uma horta, e os pais também não a cultivavam, mesmo sendo agricultores. Observa-se, nessa exposição, que, mesmo entre a população rural, não há mais uma rigidez de regras que determinam hábitos e culturas alimentares, e nem mesmo a produção para autossubsistência.

Verifica-se um movimento político muito mais personalizado em alguns atores da gestão no nível municipal que tentam barrar essa tendência de desregulação e desapego. Esse movimento conscientemente reage e intenta mudar as estruturas de maneira a convencer a população a cultivar as formas tradicionais e locais de alimentação, moldando suas práticas e escolhas de consumo alimentar desde cedo.

\section{Considerações finais}

Na contramão de um modelo dominante de produção e consumo de alimentos, o caso estudado reavalia essa relação pelo pro- 
pósito de desenvolvimento rural de um lado e, saúde de outro. Para tanto, desenvolver o rural é entendido como uma necessária descontinuidade da estrutura existente e aponta o encurtamento da cadeia de abastecimento como propósito a ser perseguido. Mas não basta desestruturar a produção, sem desestruturar o consumo. Portanto, como parte intrínseca, o consumidor deve movimentar essa engrenagem, realimentando o processo em prol da institucionalização de um novo modelo agroalimentar, o que só pode acontecer a partir da mudança das estratégias de promoção da saúde e de educação alimentar.

Assim, tratou-se de demonstrar as formas de envolver o consumidor para a revalorização do local e da revalorização da qualidade dos alimentos, principalmente no próprio meio rural. Institucionalizar novas formas de consumir encontra fortes estímulos no meio escolar, embora lutando contra ideários e práticas já muito envolvidas pela indústria alimentícia e pela mídia. Além da escola, passa-se a reunir entidades para pensar a saúde e o consumo na comunidade, enfatizando a intersetorialidade.

Essa confluência municia a contestação do modelo curativo de saúde, mas principalmente, conscientiza essa dupla interferência entre padrões de produção e padrões de consumo, extrapolando a culpabilização individual e o "deixar à própria sorte" os consumidores (considerando a sua "inteligência" para fazer escolhas), próprio do ideário liberal. Em ambas as Secretarias (Saúde e Educação), passa-se a defender um Estado interventor e ciente de seu papel relativo à defesa e manutenção do direito à saúde e relativo ao amparo de relações de mercado que sejam equitativas e morais.

Com essas considerações, defendeu-se que as mudanças institucionais dos modelos de produção e consumo só ocorrem a partir de uma dinâmica de mútuo apoio e concomitância. Não há como pensar mudança dos sistemas de produção, sem pensar em mudanças nos sistemas de consumo. Nesse caso, a estrutura pode ser mais facilmente modificada com a interferência do Estado, como um ator-chave nesse processo pelo seu poder de regulação.

Enfatiza-se que os atores (em sua maioria, representantes do Estado) - gesto- res, extensionistas, profissionais de saúde, tornam-se agentes no sentido de serem reflexivos a ponto de agir em prol das mudanças políticas e culturais que acreditavam ser necessárias. Assim, dada à tendência de individualização das escolhas e das responsabilidades que se impõe sobre a população, dentro de um cenário sem regras ou confuso para eles, faz-se necessária a conscientização e discernimento principalmente das crianças.

A institucionalização de novas cadeias alimentares inclui uma revisão das questões relacionadas às escolhas dos consumidores que baseiem sua confiança em regras relativas à proximidade e à tradição. Considerando $\mathrm{a}$ escola como espaço de socialização e multiplicação de valores, passam a ter relevância as valorações, os contextos normativos que ela providencia, influenciando nas ações e nos procedimentos dos escolares.

Também é relevante a confluência de ações que se expandem para fora do domínio escolar e toma corpo na sociedade e em outras Secretarias, como a de Saúde, por exemplo. Nesse sentido, faz diferença a forma como a saúde é tratada dentro do município, e as ações relacionadas às escolhas alimentares, propostas para a sociedade de forma mais ampla. E, também, o quanto as ações e as posturas dentro da mesma instância estatal (município) são inter-relacionadas ou se elas são dispersas e divergentes.

Essas dinâmicas assinalam importantes estratégias que determinam movimentos que consolidam novas relações de produção e consumo e que contestam/revertem a continuidade de tendências dominantes de modelos agroalimentares e de saúde coletiva.

\section{Referências}

ANJOS, L. A; BURLANDY, L. Construção do conhecimento e formulação de políticas públicas no Brasil na área de Segurança Alimentar e Nutricional. Ciência $\mathcal{E}$ Saúde Coletiva, Rio de Janeiro, v. 15, p. 19-22, 2010.

CARVALHO, S. R. Os múltiplos sentidos da categoria "empowerment" no projeto de promoção à saúde. Cadernos de Saúde Pública, Rio de Janeiro, v. 20, p. 1088-1095, 2004.

FINE, B. Debating production-consumption linkages in food studies. Sociologia Ruralis, v. 44, n.3, p.332-342, 2004.

FISCHLER, C. El (h)onívoro: el gusto, la cocina y el cuerpo. Barcelona: Anagrama, 1995. 
FREEDHOFF, Y; HÉBERT, P. C., Partnerships between health organizations and the food industry risk derailing public health nutrition. CMAJ, Canadá, v. 183, n. 3, 291-292, 2011.

GOODMAN, D; REDCLIFT, M. Refashioning nature: food, ecology and culture. London: Routledge, 1991.

GOODMAN, D; DUPUIS, E. M. Knowing food and growing food: beyond the production-consumption debate in the sociology of agriculture. Sociologia Ruralis, Wageningen, v. 42, p. 5-22, 2002.

GOODMAN, D. Rethinking food production-comsumption: integrative perspectives. Sociologia Ruralis, Wageningen, v. 42, p. 272-277, 2002.

ILBERY, B. et al. Product, process and place an examination of food marketing and labelling schemes in europe and north america. European Urban and Regional Studies, London, v. 12, p. 116-132, 2005.

KAC, G. VELÁSQUEZ-MELÉNDEZ; G., A transição nutricional e a epidemiologia da obesidade na América Latina. Cadernos de Saúde Pública, Rio de Janeiro, v. 19, p. 4-5, 2003.

LANG, T; BARLING, D; CARAHER, M. Food policy: integrating health, environment and society. UK: Oxford University Press, 2009.

LANG, T; HEASMAN, M. Food Wars: the battle for minds, mouths and markets, earthscan. London: Earthscan, 2004.

MENNELL, S; MURCOTT, A; OTERLOO, A. H. V. The sociology of food: eating, diet and culture. London: SAGE Publications, 1992.

MONTEIRO, C. A; CONDE, L. W; POPKIN, B. M. What has happened in terms of some of the unique elements of shift in diet, activity, obesity, and other measures of morbidity, and mortality within different regions of the world? Is obesity replacing or adding to under nutrition? Evidence from different social classes in Brazil. Public Journal Health and Nutrition, USA, v. 5, p. 105-112, 2002.

MORGAN, K. School Food and public domain: the politics of the public plate. The political quarterly, UK, v. 77, p. 379-387, 2006.

MORGAN, K; SONNINO, R. Empowering consumers: the creative procurement of school meals in Italy and the UK. International Journal of Consumer Studies, local, v. 31, p. 19-25, 2007.

MORGAN, K; SONNINO, R. The school food revolution: public food and the challenge of sustainable development. London: Earthscan, 2008.

SÍCOLI, J. L; NASCIMENTO, P. R. Promoção de saúde: concepções, princípios e operacionalização. Interface Comunicação, Saúde e Educação, São Paulo, v. 7, p. 101-122, 2003.

SLEE, B; KIRWAN, J. Hybrid theories for hybrid food chains? In:. WISKERKE J. S. C. et al. Sustaining food supply chains: grounded perspectives on the dynamics and impact of new modes of food provision. Aldershot: Ashgate Publishers, 2008.

TRICHES, R. M.; SCHNEIDER, S. Alimentação escolar e agricultura familiar: reconectando o consumo à produção. Saúde e Sociedade, São Paulo, v. 19, p. 933-945, 2010.

VAN DER PLOEG, J. D. et al. Rural development: from practices and policies towards theory. Sociologia Ruralis, Wageningen, v. 40, p. 392-408, 2000.

WORLD HEALTH ORGANIZATION. WORLD HEALTH ORGANIZATION. Health promotion evaluation: recommendations to policymakers. Copenhagen: European Working Group on Health Promotion Evaluation, 1998. 